\title{
QUALIDADE DE VIDA NO TRABALHO DOS PROFESSORES DE MATEMÁTICA E PORTUGUÊS DO ENSINO FUNDAMENTAL
}

\author{
Ivone Trevisan CAYE ${ }^{1}$ \\ Leandra ULBRICHT ${ }^{2}$ \\ Eduardo Borba NEVES ${ }^{3}$
}

1. Especialista em Ergonomia e Qualidade de Vida no Trabalho. Universidade Tecnológica Federal do Paraná (UTFPR), ivone.caye@uol.com.br

2. Doutora em Engenharia de Produção. Universidade Tecnológica Federal do Paraná (UTFPR), leandraulbricht@utfpr.edu.br

3. Doutor em Engenharia Biomédica. Universidade Tecnológica Federal do Paraná (UTFPR), borbaneves@hotmail.com

Recebido em: 02/10/2014 - Aprovado em: 02/12/2014 - Disponibilizado em: 15/12/2014

RESUMO: Este estudo teve como objetivo avaliar a qualidade de vida no trabalho dos professores de português e matemática de uma cidade da área metropolitana de Curitiba-PR. Foi realizada uma pesquisa exploratória com 55 professores que responderam um questionário sócio demográfico e ocupacional e o questionário sobre qualidade de vida WHOQOL-bref, desenvolvido pela OMS. As variáveis numéricas foram apresentadas por meio da estatística descritiva com medidas de posição (média) e dispersão (desvio padrão). A pesquisa revelou que a maioria dos professores (76\%), classificou positivamente a sua qualidade de vida. Contudo, na análise por domínios, enquanto o social configurou a melhor média com 73,31 pontos, o meio ambiente foi o que mais impactou negativamente na qualidade de vida dos professores com apenas 57,31 pontos.

PALAVRAS-CHAVE: Qualidade de vida. Professores. Trabalho.

\begin{abstract}
This research aimed to evaluate the quality of work life of teachers of portuguese and mathematics in a city of the metropolitan area of Curitiba - PR. We conducted a exploratory survey with 55 teachers who answered a sociodemographic and occupational questionnaire, and the questionnaire on quality of WHOQOL-bref, developed by WHO. Numerical variables were presented by descriptive statistics with measures of location (mean) and dispersion (standard deviation). The survey revealed that most teachers (76\%) ranked positively to their quality of life. However, the analysis by area, while the social set up the best average with 73.31 points, the environment was the most negative impact on quality of life of teachers with only 57.31 points.
\end{abstract}

KEYWORDS: Quality of life. Teachers. Work.

\section{INTRODUÇÃO}

A sociedade moderna transformou a vida das pessoas devido a pressão exercida no mercado de trabalho quando da procura de melhores qualificações e manutenção de emprego; as descobertas na área de medicina, doenças e tratamentos; a violência em expansão; a redução das horas ociosas, que diminuem as horas de lazer; entre outros.
Tais condições obrigaram as pessoas a fazer ajustes diários que são marcados por incertezas e adversidades, podendo levar a uma tensão diária. Essas mudanças afetaram não só positivamente, como negativamente áreas sociais como, por exemplo, hábitos de viver e se relacionar repercutindo diretamente na qualidade de vida de cada um (MINAYO;

HART; BUSS, 2000). 
A qualidade de vida hoje é um termo usado para expressar o bem-estar, felicidade e satisfação da vida como um todo. Entretanto, tal definição é subjetiva apresentando uma grande complexidade, inerente a cada pessoa ou a cada grupo social (LIPP, 1996; DÁVILA; CASA GRANDE; PEREIRA, 2010).

Segundo a Organização Mundial de Saúde (OMS) a qualidade de vida depende da compreensão que se tem no âmbito da cultura e sistema de valores nos quais se vive e em relação a objetivos, expectativas, padrões e preocupações. Tudo isso pode ser alterado por fatores internos e/ou externos (FLECK et al., 2000).

Assim, a promoção da qualidade de vida pode resultar em melhorias quanto à satisfação e motivação pessoal, o que acaba por refletir tanto dentro, como fora do ambiente de trabalho (DÁVILA; CASA GRANDE; PEREIRA, 2010).

Dantas (1999) ao apontar a qualidade de vida, como o grau maior ou menor de satisfação das carências pessoais, observa que a procura maior pela boa qualidade de vida se resume em visar situações prazerosas evitando aborrecimentos ou vivências problemáticas.

Nesse cenário, o estereótipo da vida atual dos professores, em seu ambiente de trabalho, tem contribuído para sua vulnerabilidade, fazendo com que esses profissionais possam sofrer de doenças relacionadas ao estresse $\mathrm{e}$ as doenças psicológicas (SIMPLÍCIO, 2010). Cury (2003) afirma que grande porcentagem de professores brasileiros está com três ou mais sintomas de estresse. Assim, o adoecimento dos professores, passou a afetar a qualidade de vida e conseqüentemente o rendimento no trabalho.

De acordo com Simplício (2010) ensinar pode ser uma atividade muito estressante. Assim, a qualidade na educação acaba sendo afetada pela questão do estresse, da saúde e da QVT dos docentes.

Assim, o objetivo geral desse estudo foi abordar a QVT dos professores de Matemática e Português do Ensino Fundamental das escolas públicas estaduais de uma cidade da área metropolitana de Curitiba Paraná (PR).

\section{MATERIAIS E MÉTODOS}

Quanto aos aspectos metodológicos, para os dados primários se optou pela pesquisa exploratória quantitativa que segundo Polit e Hungler (1995) ajusta o raciocínio lógico, as regras da lógica e os atributos mensuráveis da experiência humana e utiliza procedimentos estruturados e instrumentos formais para coleta de informações como: questionários, testes, entrevistas. Neste sentido, o método quantitativo destaca objetividade na coleta e verificação das informações onde os instrumentos utilizados na coleta de dados são 
testados com relação à sua confiabilidade e validade antes mesmo da coleta propriamente dita, proporcionando a análise das informações numéricas, por meio de procedimentos estatísticos.

Quanto a coletânea de dados secundários, se recorreu à técnica da pesquisa bibliográfica que "[...] é um apanhado geral sobre os principais já realizados, revestidos de importância por serem capazes de fornecer dados atuais e relevantes relacionados com o tema” (MARCONI; LAKATOS, 2010, p. 25).

Por assim ser, ressalta-se que a pesquisa bibliográfica auxiliou sobremaneira na localização de documentos como meio para se referenciar, ajudando a confrontar estudos já realizados, possibilitando a escolha de textos esclarecedores, condizentes com a proposta do trabalho.

O universo desta pesquisa é formado pela rede de educação básica (Ensino Fundamental) que possui seis escolas particulares, 22 escolas municipais e 11 escolas estaduais, com cerca de 14.747 alunos, destes 6852 matriculados nas escolas estaduais, e 727 professores dos quais 281 atuam nas escolas públicas estaduais, totalizando 100 professores, atuando na área de português e matemática.

A pesquisa foi realizada em oito das 11 escolas, uma foi excluída por ter iniciado suas atividades em agosto de 2011, e duas por falta de autorização da direção da escola.
Para a pesquisa foram utilizados 100 questionários impressos do WHOQOL-Breve e o número equivalente para o questionário sócio-demográfico e para o Termo de Consentimento Livre e Esclarecimento, destes 100 questionários distribuídos 55 foram devolvidos.

Inicialmente, elaborou-se um projeto de pesquisa, que foi entregue à Secretária de Educação do Estado do Paraná, para se obter a autorização para a realização do estudo. Com a aprovação da Secretaria de Educação do Estado o projeto foi encaminhado ao Comitê de Ética do Centro Universitário Campos de Andrade, sendo aprovado sob o número 403 em agosto de 2011. Assim, deuse continuidade aos procedimentos para a aplicação dos questionários.

Respeitando-se ainda os aspectos éticos da pesquisa houve a informação do uso do WHOQOL-Breve para o coordenador do Centro Brasileiro do grupo de QVT da OMS; e todos os entrevistados foram comunicados do objetivo da pesquisa, assinando o Termo de Consentimento Livre e Esclarecimento.

Os dados sócio-demográficos foram coletados através de um instrumento elaborado para este fim, sendo estruturado por meio de questões fechadas e a aplicação seguiu a técnica de aplicação de questionário, segundo Marconi e Lakatos (2010).

Para avaliação da Qualidade de Vida foi utilizado o WHOQOL-Bref criado pela OMS em 1998 (THE WHOQOL GROUP, 
1998), traduzido e validado à realidade brasileira por Fleck et al. (2000). Este instrumento é composto por 26 questões (facetas). Dessas, 24 representam os quatro domínios (físico, psicológico, meio ambiente e relações sociais), mais duas questões gerais sobre qualidade de vida geral. Os domínios foram calculados separadamente e são compostos pelas facetas, que são avaliadas com escores variando entre 01 e 05 , sendo 01 a condição de pior escore e 05 o melhor.

Para calcular as médias e desvio padrão utilizou-se o Software desenvolvido por Pedroso, Pilatti e Reis (2010) em Excelem que se calcula o escore "Total" do entrevistado. Trata-se do cálculo da média aritmética simples dos escores das 26 questões do instrumento. A descrição estatística de cada domínio foi calculada apresentando média e desvio padrão. As médias dos escores das questões (facetas) e domínios foram convertidas em uma escala de 0 a 100, com exceção das questões 3, 4 e 26 cujas respostas foram invertidas no momento do cálculo de cada domínio. Ou seja, no caso destas questões a condição pior está no escore 05 e a melhor no escore 01, sua inversão foi feita para fazer a comparação com as demais questões.

\section{RESULTADOS}

As principais características da amostra foram: $64 \%$ eram do gênero feminino. A idade variou de 22 a 58 anos, com média de 34,2 anos. Quanto ao estado civil, a maioria (66\%) se declarou casada. Quase metade $(45,4 \%)$ encontrava-se com o Índice de Massa Corporal (IMC) ou peso considerado normal de acordo dom os padrões estabelecidos pela OMS (segundo a tabela 1).

Tabela 1 - Características demográficas dos professores.

\begin{tabular}{lc}
\hline Características & Percentual \\
analisadas & \\
\hline Sexo & \\
Feminino & $64 \%$ \\
Masculino & $36 \%$ \\
Idade (anos) & \\
Entre 20 - 24 & $3,7 \%$ \\
Entre 25 - 29 & $12,9 \%$ \\
Entre 30 - 34 & $16,6 \%$ \\
Entre 35 - 39 & $18,5 \%$ \\
Entre 40 - 44 & $18,5 \%$ \\
Entre 45 - 49 & $14,8 \%$ \\
Entre 50 - 54 & $1,9 \%$ \\
Entre 55 - 59 & $3,8 \%$ \\
Não responderam & $9,3 \%$ \\
Estado civil & \\
Casado (a) & $66 \%$ \\
Solteiro (a) & $28 \%$ \\
Separado (a) & $4 \%$ \\
Viúvo (a) & $2 \%$ \\
IMC & \\
Abaixo de 18,5 & $3,7 \%$ \\
$\mathbf{1 8 , 5}$ a 24,9 & $45,4 \%$ \\
25 a 29,9 & $30,6 \%$ \\
30 a 34,9 & $9,2 \%$ \\
35 a 39,9 & $1,9 \%$ \\
Acima de 40,0 & $0 \%$ \\
Não responderam & 9,2 \\
\hline
\end{tabular}

Em relação ao acometimento de doenças (tabela 2), a maior parte dos entrevistados $(74,1 \%)$ respondeu não haver histórico familiar para hipertensão e diabetes, bem como não ter realizado cirurgias $(74,1 \%)$.

Verificou-se que $96,3 \%$ dos docentes responderam não possuir deficiências e uma grande parcela relatou não fazer uso de medicamentos $(79,7 \%)$. Além disso, 90,8\% 
não eram tabagistas; todos os docentes afirmaram que não ingerem, cotidianamente, bebidas alcoólicas; $85,2 \%$ não sofriam com insônia e 38,8\% dos professores entrevistados (o maior percentual encontrado) relataram dormir entre 6,1 a 7 horas por dia.

Quanto às atividades físicas, 59,3\% dos docentes declararam não realizar atividades físicas por mais de 30 minutos pelo menos duas vezes por semana e 72,2\% dos professores responderam que fazem de três a quatro refeições diárias.

Em relação ao número de anos exercendo a profissão (conforme tabela 3), verificou-se que $31,5 \%$ dos professores estão iniciando a carreira (entre 03 e 05 anos) e que $81,5 \%$ deles ministram entre 31 e 40 aulas/semanais. Estes docentes são efetivos e atuam em duas escolas em $53,7 \%$ dos casos. Os resultados obtidos referentes a outras fontes de renda mostraram que 90,8\% dos professores não possuíam outra fonte de renda.

O estudo sobre a Qualidade de Vida dos docentes de português e matemática (temática deste estudo), permitiu que fossem observadas as expectativas individuais dos professores . Assim pode-se apresentar a realidade desta autopercepção, tanto no que se refere ao trabalho, quanto às condições de vida e a insatisfação com diversos aspectos da vida.
Tabela 2 - Características e hábitos dos docentes entrevistados

\begin{tabular}{lc}
\hline Características & Percentual \\
analisadas & \\
\hline Histórico familiar com & \\
hipertensão e diabetes & \\
Sim & $25,9 \%$ \\
Não & $74,1 \%$ \\
Cirurgias realizadas & \\
Sim & $25,9 \%$ \\
Não & $74,1 \%$ \\
Possui alguma & \\
deficiência & \\
Sim & $3,7 \%$ \\
Não & $96,3 \%$ \\
Faz uso de medicamento & \\
Sim & $20,3 \%$ \\
Não & $79,7 \%$ \\
Tabagista & \\
Sim & $9,2 \%$ \\
Não & $90,8 \%$ \\
Etilista & \\
Sim & \\
Não & $0,0 \%$ \\
Atividade física superior & $100,0 \%$ \\
a 30 minutos - 02 ou & \\
mais vezes por semana & \\
Sim & \\
Não & \\
Costuma ter insônia & \\
Sim & \\
Não & \\
Refeições diárias & \\
De 1 a 2 & \\
De 3 a 4 & \\
De 5 a 6 & \\
Sono/repouso horas por & \\
dia & \\
De 5 a 6 & \\
De 6,1 a 7 & \\
De 7,1 a 8 & \\
Acima de 8 & \\
\hline
\end{tabular}

Quanto a satisfação com a própria saúde, $64 \%$ dos docentes entrevistados demonstraram estar satisfeitos; enquanto que $29 \%$ nem satisfeitos, nem insatisfeitos; 5\% insatisfeitos e $2 \%$ muito satisfeitos.

Chama a atenção o alto índice de professores que avaliam positivamente a sua Qualidade de Vida (76\%). Sendo que $67 \%$ dos professores afirmaram possuir uma boa 
qualidade de vida geral; $13 \%$ nem boa, nem ruim; $11 \%$ ruim; $9 \%$ muito boa.

Segmentando-se as informações relativas a Qualidade de Vida em domínios (Tabela 4), verificou-se que a percepção dos professores entrevistados quanto à qualidade de vida no domínio físico atingiu média de 71,16\%. As facetas: Dor e desconforto, dependência de medicação ou de tratamento e sentimentos negativos obtiveram os escores mais baixos. Dentre os entrevistados, $66,20 \%$ demonstraram satisfação com sua capacidade de desempenhar as atividades no dia-a-dia. Outras questões como: energia e fadiga, sono e repouso, capacidade para o trabalho apresentaram melhores resultados.

Tabela 3 - Características ocupacionais dos professores.

\begin{tabular}{lc}
\hline Características analisadas & Percentual \\
\hline \multicolumn{1}{c}{ Tempo que estão lecionando } \\
(anos) & \\
Entre 1 e 2 & $3,7 \%$ \\
Entre 3 e 5 & $31,5 \%$ \\
Entre 6 e 10 & $29,7 \%$ \\
Entre 11 e 15 & $24,0 \%$ \\
Entre 16 e 20 & $3,7 \%$ \\
Mais de 20 & $7,4 \%$ \\
Número de aulas semanais & \\
1 à 10 & $0,0 \%$ \\
11 à 20 & $3,7 \%$ \\
21 à 30 & $1,8 \%$ \\
31 à 40 & $81,5 \%$ \\
Mais de 40 & $13,0 \%$ \\
Número de escolas em que & \\
trabalha & \\
1 & $38,8 \%$ \\
2 & $53,7 \%$ \\
Acima de 4 & $5,5 \%$ \\
Vínculo empregatício & $2,0 \%$ \\
Efetivo & \\
Contratado & $53,7 \%$ \\
Exerce outra atividade & $46,3 \%$ \\
Sim & \\
Não & $9,2 \%$ \\
\hline
\end{tabular}

No domínio psicológico a média obtida foi de $70,68 \%$, a faceta 'sentimentos negativos' obteve o escore mais baixo. A maioria dos professores mostrou-se satisfeita com sua imagem corporal e aparência física, considerando que sua vida tem sentido e além disso, possuem elevada auto-estima.

Tabela 4 - Percepção dos professores quanto à qualidade de vida segundo os domínios

\begin{tabular}{lcc}
\hline Domínio & Média & Desvio padrão \\
\hline Físico & 71,16 & 12,55 \\
Psicológico & 70,81 & 11,30 \\
Relações sociais & 73,31 & 11,95 \\
Meio ambiente & 57,31 & 13,00 \\
\hline
\end{tabular}

Em relação ao domínio das relações sociais o resultado foi ainda maior $(73,30 \%)$ e todas as facetas deste domínio: relações pessoais; suporte (apoio) social e atividade sexual obtiveram bons resultados.

$\mathrm{Na}$ questão do domínio meio ambiente, encontrou-se a média mais baixa $(57,64 \%)$. De todas as facetas deste domínio as mais representativas na obtenção desta média mais baixa foram: ambiente físico; recreação e lazer; recursos financeiros e cuidados da saúde e sociais (disponibilidade e qualidade). Em adição, 42,59\% dos professores relataram que estão insatisfeitos com o ambiente de trabalho devido ao número excessivo de alunos por sala de aula, sala de aula em péssimas condições como, por exemplo, vidros de janelas quebrados. Quanto ao lazer, $48,61 \%$ dos professores afirmaram que tem pouca ou nenhuma oportunidade de lazer. Além disso, 52,78\% dos professores relataram que o dinheiro que possuem não é 
suficiente para atender às suas necessidades e $55,56 \%$ estão insatisfeitos com o acesso aos serviços de saúde.

As outras questões deste domínio apresentaram melhores resultados: $67,13 \%$ afirmaram estar satisfeitos com a segurança física; 68,98 relataram que estão satisfeitos ou muito satisfeitos com o local onde moram; $61,57 \%$ dos professores relataram que estão satisfeitos com o transporte e $63,89 \%$ dos professores consideram que as informações que necessitam estão muito disponíveis.

\section{DISCUSSÃO}

No que se refere à saúde, grande parte dos trabalhos realizados tem como base uma perspectiva na qual saúde é entendida como ausência de doença. A saúde, ao contrário da doença, que é facilmente identificável, é difícil de definir, pois uma pessoa pode aparentemente ser forte e resistente aos danos físicos e às pressões da vida cotidiana e ainda assim ter problemas mentais ou psicológicos. Assim, a saúde pode ser definida, inicialmente, “[...] como a capacidade física, emocional, mental e social de um indivíduo de forma que o mesmo possa interagir com seu ambiente" (DANTAS, 1999, p.2).

Um fator de muito peso na preservação da saúde de um indivíduo é a sua percepção de que ele está contribuindo para a vida em sociedade, sendo de alguma forma útil para alguém ou para alguma instituição. É extremamente revigorante, inclusive para a própria auto-estima, descobrir que pessoas estão sendo beneficiadas através da sua atuação.

O estereótipo da vida atual tem contribuído para uma vulnerabilidade dos indivíduos, por serem cada vez mais acometidos de doenças relacionadas ao estresse e vários trabalhos identificam o trabalho do professor com o estresse. Alguns, apontam o aumento do ritmo de vida e de trabalho como a causa: correria de escola para escola, de uma sala de aula para outra, de um conteúdo para outro, de casa para o trabalho e do trabalho para casa, em cadências marcadas pelo relógio, horários e calendários; professores movidos pela necessidade e sentimento de que é preciso aproveitar o tempo e compatibilizar com suas responsabilidades de pais, mães, cidadãos, os ritmos do tempo do trabalho dos professores são muito particulares, confortando hábitos, estilos de vida e modos de ser, constitutivos de suas identidades (TEIXEIRA, 1999).

Outros como Siman (2006), o associam as falhas do sistema educacional que têm contribuído para o julgamento negativo por parte da sociedade e dos pais de alunos, pelo fracasso da escola pública. A autora descreve que esta realidade incomoda profundamente os professores, que se ressentem coletivamente, pois, apesar do esforço e de trabalharem com todas as adversidades, não tem os seus trabalhos reconhecidos e valorizados. $\mathrm{O}$ que tem 
causado um aumento de adoecimento e afastamento desses profissionais.

Um estudo realizado por Codo (1999), sobre saúde mental dos professores no Brasil, indicou que $26 \%$ da amostra apresentavam esgotamento emocional, sendo a desvalorização profissional, a pouca autoestima e a falta de resultados percebidos no trabalho, os principais fatores para a configuração deste quadro. Os resultados apresentam como aspecto fundamental do processo de sofrimento dos professores, a perda crescente do controle de seu desempenho no trabalho e a progressiva desmotivação para ensinar.

A avaliação da QVT pelo WHOQOLbref teve por finalidade, quantificar a percepção subjetiva dos professores com relação aos domínios físico, psicológico, social, ambiente e auto-percepção de qualidade de vida, de modo a obter um índice para cada domínio que serão discutidos a seguir.

\section{Quanto ao perfil sócio-demográfico da amostra}

Os dados sócio demográficos revelaram que $64,81 \%$ dos pesquisados são do sexo feminino, dados semelhantes aos estudos de Siman (2006), em seu estudo com professores de quatro escolas públicas estaduais de Coronel Fabriciano-MG com uma amostra de 120 professores, e Neves (2008), que realizou uma pesquisa com 601 professores de escolas públicas, estaduais e municipais de ensino fundamental e médio da zona urbana de Pelotas-RS.

Em relação à idade média dos professores, verifica-se que eles são jovens (37,08 anos), tendo o mais novo 22 anos e o mais velho 58 anos; dados semelhantes aos encontrados por Penteado e Pereira (2007), em um estudo sobre a qualidade de vida e saúde vocal realizado com 128 professores de ensino médio de quatro escolas estaduais de Rio Claro-SP. E também, muito próximo da média 36,05\% identificada nos estudos de Rocha e Fernandes (2008) sobre qualidade de vida de professores do ensino fundamental, com 91 professores do ensino fundamental da rede municipal de Jequié-BH.

Segundo informações de Ghorayeb e Barros (1999) cerca de 40\% da população já apresentam sintomas de obesidade e, portanto, não haveria justificativa para não se ter hábitos saudáveis, a fim de garantir não só o aumento de longevidade, mas também um incremento na qualidade de vida. A pesquisa demonstrou que em 45,4\% da amostra o IMC apresentou um índice abaixo de $25 \mathrm{~kg} / \mathrm{m}^{2}$ considerado como normal e 41,7\% acima deste. Este resultado foi um pouco acima do encontrado por Oliveira Filho (2009), que realizou um estudo com 288 professores da Universidade Estadual de Maringá (PR) e apontou que $36,81 \%$ destes indivíduos estavam com excesso de peso. 
A prevalência do tabagismo foi de $9,2 \%$, podendo ser considerado um valor relativamente baixo se comparado a outros estudos como o de Monteiro et al. (2005) que encontraram uma prevalência de $19,7 \%$ de fumantes na cidade de São Paulo. Considerando o hábito de fumar sobre a qualidade de vida, o estudo de Castro et al. (2007) sobre qualidade de vida e dependência do tabaco, realizado com 276 dependentes de tabaco, revelou uma associação inversa entre maior dependência de tabaco (maior número de cigarros) e menores escores em todos os domínios de qualidade de vida.

Quanto ao consumo frequente de álcool, inexistente, segundo os relatos da amostra pesquisada, também é um resultado que difere de outras pesquisas como a de Oliveira Filho (2009), que revelou um consumo excessivo de álcool (67,01\%), entre os professores universitários de Maringá-PR.

Nesta amostra 59,3\% são considerados sedentários. Este resultado coincide com o encontrado por Oliveira Filho (2009), mas ficando muito acima ao valor encontrado por Petroski (2005) numa amostra de 366 Professores da Universidade Federal de Santa Catarina-UFSC, na qual apenas 8,2\% dos professores foram classificados como sedentários.

Considerando o impacto do excesso de peso, associado a falta de uma atividade física regular e hábitos alimentares não saudáveis que podem causar impactos na saúde dos professores, principalmente quanto as doenças cardiovasculares; deveriam ser criadas estratégias para incentivar a atividade física e hábitos alimentares mais saudáveis a um estilo de vida mais ativo, que são de suma importância para alçar e manter melhores percepções de qualidade de vida.

Em relação ao número de aulas $81,5 \%$ dos professores entrevistados ministram em média 40 aulas/semanais. Os resultados por obtidos por Neves (2008) em um estudo sobre Trabalho docente e qualidade de vida na rede pública de Pelotas-RS, revelam dados similares. Em seu estudo, a carga horária média de 40 horas em sala foi de 88,9\%. Considerando-se a carga horária ligada à docência, mais as tarefas de preenchimento de diários de classe e a programação dos conteúdos a serem trabalhados, tem-se que a jornada total do professor aumenta sensivelmente.

\section{Quanto a Qualidade de Vida}

Quanto a auto percepção da qualidade de vida, $67 \%$ dos professores descrevem possuir uma boa qualidade de vida (tabela 5). Esse índice foi similar nos estudos de Penteado e Pereira (2007) que encontraram um índice de $65,5 \%$ em estudo realizado com professores do Ensino Médio de escolas públicas em Rio Claro-SP, e de Bittencourt (2005) em estudo com professores do ensino fundamental de Palotina-PR que apresentaram um índice de $65 \%$ na avaliação de sua 
qualidade de vida geral, cabe ressaltar que os dois foram realizados com professores de escolas públicas e de ensino fundamental e médio em que as condições de trabalho e o nível econômico coincidem com a deste estudo.

Tabela 5 - Auto-percepção quanto a Qualidade de Vida e Saúde

\begin{tabular}{ccc}
\hline $\begin{array}{c}\text { Auto percepção } \\
\text { da QV e Saúde }\end{array}$ & Q.V & Saúde \\
\hline Resultado desta pesquisa & $\mathbf{6 7 , 0 0 \%}$ & $\mathbf{6 4 , 0 0 \%}$ \\
Penteado e Pereira (2007) & $\mathbf{6 6 , 0 0 \%}$ & $\mathbf{6 0 , 2 0 \%}$ \\
Silva e Nunez (2009) & $\mathbf{7 4 , 4 0 \%}$ & - \\
Oliveira Filho (2009) & $\mathbf{8 4 , 3 7 \%}$ & $\mathbf{7 6 , 7 4 \%}$ \\
Neves (2008) & $\mathbf{7 0 , 0 0 \%}$ & $\mathbf{5 1 , 8 0 \%}$ \\
Siman (2006) & $\mathbf{5 2 , 5 0 \%}$ & $\mathbf{5 4 , 2 0 \%}$ \\
\hline
\end{tabular}

Os dados encontrados por Dávila, Casagrande e Pereira (2010) com professores universitários de Curitiba-PR foram mais elevados, onde $75 \%$ afirmaram que sua qualidade de vida boa ou muito boa, mas ainda abaixo dos $76 \%$ encontrados nesta pesquisa (considerando-se o agrupamento de respostas boa ou muito boa).

A melhor percepção de qualidade de vida foi encontrada pelo estudo de Oliveira Filho (2009), com professores universitários da Universidade Estadual de Maringá-PR que observou $84,37 \%$ de amostra com uma Qualidade de vida boa ou muito boa.

Quanto a satisfação com a própria saúde, verificou-se que $93 \%$ dos pesquisados demonstraram uma percepção positiva da saúde, entre satisfeitos e muito satisfeitos. No estudo de Penteado e Pereira (2007), o grupo de docentes do ensino médio $60,2 \%$ relatou apenas "satisfação" com a saúde não havendo relatos de "muito satisfeitos".

Já no estudo de Oliveira Filho (2009) com professores universitários de MaringáPR, a amostra denota uma percepção média de $76,74 \%$ entre satisfeitos e muito satisfeitos com sua saúde, média também inferior ao encontrado neste estudo.

Ressalta-se que, de acordo com a OMS (2011), saúde é um estado completo de bem-estar físico, mental e social e não apenas a ausência de doença e enfermidade, sendo a saúde então um fator de grande importância na percepção da qualidade de vida. Assim percebeu-se que a boa qualidade de vida no trabalho exerce grande influência sobre a auto-estima dos docentes.

$\mathrm{Na}$ avaliação da qualidade de vida através do instrumento Whoqol-breve, devese pontuar os quatro domínios de forma independente, considerando que qualidade de vida é um construto multidimensional entre todos os domínios.

$\mathrm{Na}$ tabela 6, foi realizada uma comparação dos estudos realizados com professores, lembrando que os estudos de Dávila, Casagrande e Pereira (2010), foi realizado com professores universitários, assim como o estudo de Oliveira Filho (2009), os demais estudos foram realizados com professores de escolas públicas. 
Tabela 6 - Comparação com outros estudos - domínios do whoqol-breve

\begin{tabular}{|c|c|c|c|c|}
\hline Domínios & Físico & Psicológico & $\begin{array}{l}\text { Relações } \\
\text { sociais }\end{array}$ & $\begin{array}{l}\text { Meio } \\
\text { ambiente }\end{array}$ \\
\hline $\begin{array}{l}\text { Resultados } \\
\text { desta } \\
\text { pesquisa }\end{array}$ & $71,16 \%$ & $70,81 \%$ & $73,31 \%$ & $57,31 \%$ \\
\hline $\begin{array}{l}\text { Penteado e } \\
\text { Pereira } \\
(2007)\end{array}$ & $68,20 \%$ & $68,20 \%$ & $\mathbf{7 0 , 3 0 \%}$ & $56,10 \%$ \\
\hline $\begin{array}{l}\text { Xavier e } \\
\text { Silva (2004) }\end{array}$ & $68,57 \%$ & $68,96 \%$ & $67,71 \%$ & $56,64 \%$ \\
\hline $\begin{array}{l}\text { Silva e } \\
\text { Nunez (2009) }\end{array}$ & $58,75 \%$ & $65,22 \%$ & $75,24 \%$ & $60,64 \%$ \\
\hline $\begin{array}{l}\text { Oliveira } \\
\text { Filho (2009) }\end{array}$ & $64,90 \%$ & $61,10 \%$ & $81,90 \%$ & $54,80 \%$ \\
\hline $\begin{array}{l}\text { Dávila, } \\
\text { Casagrande e } \\
\text { Pereira(2010) }\end{array}$ & $\mathbf{7 7 , 8 4 \%}$ & $86,75 \%$ & $85,04 \%$ & $85,02 \%$ \\
\hline Neves (2008) & $69,20 \%$ & $70,60 \%$ & $72,48 \%$ & $60,15 \%$ \\
\hline Siman (2006) & $65,90 \%$ & $68,30 \%$ & $\mathbf{7 0 , 3 0 \%}$ & $49,70 \%$ \\
\hline
\end{tabular}

\section{Domínio meio ambiente}

Analisando os resultados por domínios, percebeu-se que o domínio meio ambiente apresentou-se como o de menor nível $(57,64 \%)$ de qualidade de vida, conforme apresentação na Tabela 4 , as facetas que colaboraram para a sua baixa pontuação foram: oportunidades de recreação e lazer e ambiente físico (poluição, ruído, clima).

Aspectos como oportunidades de lazer ajudaram na obtenção de uma média baixa deste domínio. Ao serem indagados sobre as suas oportunidades de lazer, 48,14\% dos professores responderam que possuem uma média oportunidade de lazer e $25,92 \%$ disseram que possuem muito poucas oportunidades de lazer.

Esse resultado permitiu concluir que a profissão de docente não permite muito tempo livre para os professores usufruírem das atividades de lazer, pois sua atribuição não se limita somente ao ambiente escolar, muitas vezes levam 'trabalho para casa', tornando o tempo disponível para o lazer menor ainda. (SILVA; NUNEZ, 2009).

O domínio meio ambiente também pode ser relacionado com as condições de trabalho, porque neste domínio existem facetas que visam às condições de meio ambiente (clima, barulho, poluição). Penteado e Pereira (2007) em estudo com professores do Ensino Médio de quatro escolas estaduais de Rio Claro-SP demonstraram que o domínio meio ambiente quando comparado aos demais domínios, apresenta-se o mais prejudicado com média de 56,1\%. Já para Siman (2006) em seu estudo com professores das escolas públicas estaduais de Coronel FabricianoMG, encontrou resultados inferiores, 49,7\%.

No estudo realizado por Dávila, Casagrande e Pereira (2010) realizado com professores universitários, o domínio meio ambiente obteve média superior a esta pesquisa com média de $85,02 \%$.

\section{Domínio psicológico}

O valor encontrado para o domínio Psicológico nesta pesquisa $(70,68 \%)$ foi muito semelhante ao estudo de Neves (2008) com 601 professores das escolas públicas estaduais e municipais de ensino fundamental e médio da zona de Pelotas-RS, cujo valor médio foi de $70,6 \%$. 
Já o estudo de Xavier e Silva (2004), com 40 professores do ensino fundamental da rede pública estadual de ensino de Aracajú-SE obteve uma média de $68,96 \%$, resultado um pouco abaixo dos desta pesquisa. Assim também com o estudo de Penteado e Pereira (2002), em um estudo realizado com 128 professores do ensino médio de quatro escolas estaduais de Rio Claro-SP, que apresentaram um escore com média de $68,2 \%$.

Porém os estudos mais discrepantes foram o de Oliveira Filho (2009), realizado com 288 professores do ensino superior da Universidade Estadual de Maringá-PR que apresentou uma média de $61,1 \%$ e o de Dávila, Casagrande e Pereira (2010) com 39 professores universitários de uma instituição de ensino de Curitiba-PR, que apresentou um escore de $86,75 \%$ (bem superior aos encontrados nesta pesquisa).

\section{Domínio físico}

No domínio físico $(71,16 \%)$, observam-se as percepções relacionadas às facetas que correspondem à dor física, energia para o dia a dia, o sono, a locomoção, as atividades da vida diária, ao tratamento dependência de medicamentos ou de tratamentos, e a capacidade de trabalho. Analisando os resultados observou-se que as facetas, energia e fadiga $(64,81 \%)$, sono e repouso $(61,11)$, apresentaram escores baixos.

Nos estudos de Penteado e Pereira (2007), com 128 professores do ensino médio público de Rio Claro-SP apresentaram uma média de $68,2 \%$, resultado que se aproxima aos desta pesquisa, bem como do valor de $68,57 \%$ encontrado por Xavier e Silva (2004), com professores do ensino fundamental da rede pública de Aracajú-SE.

O estudo de Oliveira Filho (2009) realizado com com 288 professores da Universidade Estadual de Maringá-PR que apresentou média de 64,90\%, mas ainda superior ao de Silva e Nunez (2009), que pesquisaram 69 professores de educação física de escolas públicas de Campo GrandeMS e identificaram para este domínio uma média de $58,75 \%$.

Já o estudo de Dávila, Casagrande e Pereira (2010), realizado com 39 professores de uma instituição de ensino superior, os resultados estão superiores a esta pesquisa $(77,84 \%)$.

Segundo Mendes et al. (1995), a fadiga é um sintoma que se apresenta na síndrome conhecida como Burnout. Esta síndrome se caracteriza por uma constante sensação de cansaço, má qualidade do sono, dores de cabeça e no corpo, perda do apetite, irritabilidade e desânimo, levando a diminuição da qualidade de vida no trabalho.

Segundo Levy (2007), a classe docente torna-se mais vulnerável à doença devido às exigentes condições de trabalho que lhe são impostas e ao esgotamento diário que o trabalho provoca. Jornada de trabalho excessiva, falta de limites do público infanto- 
juvenil, transferência da educação infantil da família para a sala de aula, baixos salários e sistema precário são apenas alguns dos problemas que fazem parte da rotina de professores do ensino público brasileiro (NEVES, 2008).

\section{Domínio relações sociais}

No domínio social os professores desta pesquisa apresentaram a melhor média $73,3 \%$, lembrando que as facetas avaliadas são: relações pessoais; apoio social e atividade sexual. Apresentaram resultados semelhantes a pesquisa de Penteado e Pereira (2007) envolvendo professores do ensino médio de escolas estaduais de Rio Claro-SP com 70,3\% e Siman (2006), cuja pesquisa com 120 professores de escolas públicas estaduais de Coronel Fabriciano-MG, obteve um escore médio de 70,3\%.

Porém analisando o estudo de Dávila, Casagrande e Pereira (2010) com professores universitários de uma instituição de ensino superior de Curitiba a média apresentada foi de $85,04 \%$ (bem acima da relatada por esta pesquisa).

Por outro lado, o estudo de Xavier e Silva (2004), realizado com 40 professores do ensino fundamental de escolas públicas de Aracajú-SE, obtive média de 67,71\%, ou seja, um valor abaixo do relatado nas demais pesquisas apresentadas.

Ao analisar as respostas por facetas, salienta-se a referente a questão 26 que se refere à frequência de sentimentos negativos tais como mau humor, desespero, ansiedade, depressão; as respostas foram as seguintes: nunca (36\%); algumas vezes (44\%); freqüentemente $(12 \%)$; muito freqüentemente $(6 \%)$ e sempre $(2 \%)$.

Percebe-se que $36 \%$ dos docentes nunca se sente afetado, mesmo após uma longa exposição a agentes estressores, como é a vida dos professores atualmente, onde fatores como: a insatisfação no trabalho, a falta de motivação e falta de atividades de lazer podem resultar em sentimentos negativos,tendo a possibilidade de aumentar ou agravar a tensão. Isto se deve provavelmente, ao pouco tempo de profissão da amostra pesquisada onde ainda não existe uma alta prevalência de relatos quanto aos sentimentos de inutilidade, diminuição de auto estima, que acabam por diminuir a percepção da qualidade de vida no trabalho.

Limongi-França e Rodrigues (2005) afirmam que quanto maior $o$ comprometimento do indivíduo com um grupo ou uma organização maior terá de ser a sua dedicação, assim, maior será sua ansiedade para atender as expectativas, conseqüentemente, maior sua tendência para a diminuição da qualidade de vida no trabalho.

\section{CONSIDERAÇÕES FINAIS}

Os professores pertencem a uma classe de profissionais especialmente expostos aos riscos psicossociais, por estarem defrontando- 
se com fatores desencadeantes de estresse próprios da organização acadêmica e escolar e com situações nas quais se desequilibram as expectativas individuais do profissional e a realidade do trabalho diário.

Nesta pesquisa identificou-se que o domínio relações sociais (que inclui os tópicos: satisfação com as relações pessoais, vida sexual e apoio de familiares, amigos e colegas de trabalho), apresentou-se com o melhor resultado $73,3 \%$, impactando de forma positiva na qualidade de vida dos professores analisados.

Diante dos resultados encontrados conclui-se que os professores de português e matemática tem boa percepção sobre sua qualidade de vida geral no contexto do trabalho, no entanto o resultado obtido no domínios meio ambiente não foi satisfatório. Este domínio formado por aspectos como: insatisfação, insuficiência ou falta de: lazer, dinheiro, acesso às informações, serviço de saúde, transporte e ambiente de trabalho, quando não satisfatório pode evidenciar a desvalorização do professor.

Com relação ao ambiente de trabalho $81,4 \%$ dos professores responderam que o ambiente é muito pouco ou mais ou menos saudável, confirmando dados da literatura sobre as condições negativas de trabalho, citando-se: salas quentes e mal ventiladas com presença de poeira, sujeira e pó de giz, ruídos internos e externos, além de problemas na organização do trabalho, com relações sociais estressantes, rodadas com sentimentos negativos como agressividade, indisciplina, desrespeito e violência.

Finalizando este estudo, se recomenda para trabalhos futuros novas abordagens que possibilitem compreender e incentivar estilos de vida mais saudáveis e compatíveis com o dia a dia dos docentes das escolas públicas estaduais do Paraná.

\section{REFERÊNCIAS}

BITTENCOURT, M. G. S. Q. 134f. Qualidade de vida do professor do ensino fundamental da rede pública municipal de Palotina-PR. Dissertação (Mestrado em Psicologia) - Universidade Católica Dom Bosco. Campo Grande, 2005.

CASTRO, M, G. et al. Qualidade de vida e gravidade da dependência do tabaco. Revista de Psiquiatria Clínica, Porto Alegre, v.34, n.2, p.61-67, 2007.

\section{CODO, W. Educação: Carinho e trabalho.} Petrópolis: Vozes, 1999.

CURY, A. Pais brilhantes, professores fascinantes. Rio de Janeiro: Sextante, 2003.

DANTAS, E. H. M. Flexibilidade, alongamento e flexionamento. 4. ed. Rio de Janeiro: Shape, 1999.

DÁVILA, M. H. X.; CASAGRANDE, R. J. T.; PEREIRA, V. C. G. Qualidade de vida do trabalhador de uma instituição de ensino. Cadernos da Escola de Saúde, Curitiba, v.1, n.4, p.110-126, 2010.

FLECK, M. P. A. et al. Aplicação da versão em português do instrumento abreviado de avaliação da qualidade de vida WHOQOLBref. Revista Saúde Pública, São Paulo, v.34, n.2, p.178-83, abr. 2000.

GHORAYEB, N.; BARROS, T.. O Exercício: preparação fissiológica, avaliação médica, aspectos especiais e preventivos. São Paulo: Atheneu, 1999. 
LEVY, G. Professores à beira de um ataque de nervos. Agência UERJ, Rio de Janeiro, 2007. Disponível

em: http://www2.uol.com.br/vivermente/noticias/p rofessores_a_beira_de_um_ataque_de_nervos .html. Acesso em: 19 nov. 2011.

LIMONGI-FRANÇA, A. C; RODRIGUES, A. L. Stress e trabalho: uma abordagem psicossomática. São Paulo: Atlas, 2005.

LIPP, M. E. N. Pesquisas sobre stress no Brasil: saúde, ocupações e grupos de risco. Campinas: Papirus, 1996.

MARCONI, M. A.; LAKATOS, E. M. Técnicas de pesquisa. 7 ed. São Paulo: Atlas, 2010.

MENDES, R. Patologia do trabalho. Rio de Janeiro: Atheneu, 1995.

MINAYO, M. C. S.; HARTZ, Z. M. A.; BUSS, P. M. Qualidade de vida e saúde: um debate necessário. Revista Ciência \& Saúde Pública, v.5, n.1. Rio de Janeiro, p.7-18, 2000.

MONTEIRO, C. A. et al. Monitoramento de fatores de risco para doenças crônicas por entrevistas telefônicas. Revista Saúde Pública, São Paulo, v.39, n.1, p.47-57, 2005.

NEVES, S. F. Trabalho docente e Qualidade de Vida na Rede Pública de Ensino de Pelotas. 104 f. Dissertação (Mestrado em Política Social) - Universidade Católica de Pelotas. Pelotas, 2008.

OLIVEIRA FILHO, A. Indicadores relacionados à qualidade de vida $\mathrm{e}$ fatores de risco de professores da Universidade Estadual de Maringá - PR. 103 f. Dissertação (Mestrado em Educação Física) Universidade Estadual de Maringá, Maringá, 2009.

OMS. ORGANIZAÇÃO MUNDIAL DA SAÚDE. Versão em português dos instrumentos de avaliação da Qualidade de Vida (WHOQOL). Porto Alegre, 1998. Disponível em: <www.ufrgs.br/psiq>. Acesso em: 10 mai. 2011.

PEDROSO, B.; PILATTI, L. A.; REIS, D. R.. Cálculo dos escores e estatística descritiva do WHOQOL-bref através do Microsoft Excel.
Revista Brasileira de Qualidade de Vida, Ponta Grossa, v.2, n.1, p.31-36, jan/jun. 2010.

PENTEADO, R. Z; PEREIRA, I. M. T. B. Qualidade de vida e saúde vocal de professores. Revista Saúde Pública, v.41, n.2, p.236-43, 2007.

PETROSKI, E. C. Qualidade de vida no trabalho e suas relações com o estresse, nível de atividade física e risco coronariano de professores universitários. $170 \mathrm{f}$. Tese (Doutorado em Engenharia de Produção e Sistemas) - Universidade Federal de Santa Catarina, Florianópolis, 2005.

POLIT, D. O'Hara; HUNGLER, B. P. Fundamentos de pesquisa em enfermagem: métodos, avaliação e utilização. 5. ed. Porto Alegre/RS: Artes Médicas, 1995.

ROCHA, V. M.; FERNANDES, M. H. Qualidade de vida de professores do ensino fundamental: uma perspectiva para a promoção da saúde do trabalhador. Jornal Brasileiro de Psiquiatria, v.57, n.1, p.21-9, 2008.

SILVA, J. V. P.; NUNEZ, P. R. M. Qualidade de vida, perfil demográfico e profissional de professores de educação física. Revista Pensar a Prática, v.12, n.2, p.1-11, 2009.

SIMAN, Y. V. Análise da organização do trabalho, saúde e qualidade de vida dos professores das escolas estaduais de Coronel Fabriciano-MG. 110 f. Dissertação (Mestrado em Meio Ambiente e Sustentabilidade) - Centro Universitário de Caratinga, Caratinga, 2006.

SIMPLÍCIO, S. D. Estudo sobre a relação trabalho e saúde de professores da rede pública municipal de São Paulo. 107 f. Dissertação (Mestrado em Psicopedagogia) Centro Educacional FIEO, SP. Disponível em $<$ http://www.unifieo.br>. Acesso em: 15 mai. 2011.

TEIXEIRA, I. A. C. Cadência escolar, ritmos docentes. Revista Educação e Pesquisa, São Paulo, v.25, n.2, p.87-108, 1999.

XAVIER, C. E. S.; SILVA, R. J. S. Qualidade de vida em professores da Rede Pública Estadual de Ensino da cidade de Aracaju (SE). In: VI Simpósio Nordestino de 
Atividade Física e Saúde, 2004, Recife. Anais do VI Simpósio Nordestino de Atividade

Física e Saúde. Recife: UPE, 2004. 